\title{
How to Be a Superforecaster
}

\section{FOR FINANCIAL ANALYSTS, SUCCESS REQUIRES MORE THAN JUST ACCURATE PREDICTIONS}

By Ralph Wanger, CFA

Forecasting the price of a stock is not easy. Markets are effective mechanisms for collecting widely dispersed information and distilling it down to a single judgment: price. The strong form of the efficient market hypothesis says forecasting can't be done. The enormous growth of indexing over the past 30 years shows that investors have concluded that the possible gains from active investing do not compensate them for the increased risk. So, what should a financial analyst do to justify riches and fame?

To create value, you need to discover something about the future that is not generally known-to forecast. You'd better have a skill that helps your organization gather assets and form superior portfolios; if massaging data is all you do, you are a historian or journalist, not an analyst. If people forecast so badly now, there must be a way to do it better. How could the forecasting process be improved?

Because active investing is now on the defensive, you could ask the question, "Can anybody say anything useful about the future?" There are many times when things that should have been reasonably obvious were missed by all the experts. One such example-and one I observed firsthandwas leading up to the fall of the Berlin Wall in 1989. I went on a series of trips to West Germany and East Germany in the late 1980s. The trips were arranged by the Aspen Institute in Berlin, which organized a study group of 30 US experts on Germany and 30 German experts on the United States. We had academics, diplomats, military officers, and business people, all keen students of Germany and its neighbors. Even 25 years later, I still have high regard for the people involved.

The group, centered in Berlin, traveled extensively through West and East Germany and met with lots of important and well-informed people. Many of them had important posts in Germany or the US. But-six months before the Berlin Wall came down and Eastern Europe left the Soviet blocabsolutely none of the 60 members of our group had the slightest suspicion that this was going to happen. Maybe this example proves that "nobody can predict nothing no place."

A contrary opinion, however, was published in September 2015 with Superforecasting: The Art and Science of Prediction, by Philip Tetlock and Dan Gardner. Tetlock, the Leonore Annenberg University Professor in Democracy and Citizenship at the University of Pennsylvania, has been able to identify many people who could be turned into what he calls "superforecasters"-people whose analytic ability is considerably better than random (or who, in financial analyst terms, "beat the market"). Analysts have to do many things besides forecast, but the ability to make better predictions would certainly give a substantial edge to many of us.

According to Tetlock, if you want to be a superforecaster, you must have four key traits (although he lists additional traits as well). First, you need to be very intelligent but not an off-the-charts genius. Second, you must be a solver of puzzles and a player of games. Third, you must pragmatically use other people's ideas. Fourth, you must be willing to change your mind when new data shows up.

These traits describe an analyst in part but, more importantly, they help distinguish an analyst from a journalist.

In addition to the general traits of a superforecaster, to be a successful financial analyst, you must possess three other skills:

1. Long-term and detailed knowledge of a few industries.

2. Friends inside many companies who can help you understand important trends (this does not include illegal insider information), giving you the ability not only to make a point forecast (e.g., oil prices will be higher in three months) but also to predict structural changes (e.g., teen apparel stores in the mall are losing market share to Amazon).

3. Communication skills, because the ability to speak and write convincingly will be necessary to get your ideas implanted. Success as a financial analyst depends on leverage, defined as the quality of an idea multiplied by the amount of money that is put into the idea. To get that leverage, you must sell your colleagues on it.

Any analyst can get some useful ideas from Superforecasting, but the person in your company who most needs to read it is the director of research. There are valuable ideas about how to hire people who can think about future events in a useful way-as well as ideas about training and managing them once they're hired.

One of the most interesting ideas is how to form a research group (rather than a collection of analysts who each work on their own). Tetlock presents good examples showing that groups of forecasters have an advantage in providing superior forecasts.

Although forecasting groups can do better than individuals, getting a collection of creative but independent spirits to work together-in a true collaborative effort instead of as a collective-is really hard to do. The examples of superforecasters in the book are people who are essentially volunteers and hobbyists, not highly paid employees of a profit-making company. Devising a fair compensation policy for a group of egotistical and ambitious investment professionals who work both on their own and as members of a group may well cause the director of research to seek a less stressful job-perhaps as a lion tamer at the circus.

Ralph Wanger, CFA, is a trustee of Columbia Acorn Trust. 